\title{
Metastatic Appendix Carcinoma
}

National Cancer Institute

\section{Source}

National Cancer Institute. Metastatic Appendix Carcinoma. NCI Thesaurus. Code C162275.

Carcinoma of the appendix that has spread from the original site of growth to other anatomic sites. 